\title{
5. Sexual Abuse of Children and Adolescents:
} Prevalence and Trends

\author{
Lena Posch, Steffen Bieneck
}

\subsection{Introduction}

The widely debated cases of institutional sexual abuse that have come to light in increasing numbers since early 2010 have once more brought the issue to general notice and highlighted the need for up-to-date figures on the prevalence and experience of abuse in childhood and adolescence. Alongside absolute prevalence rates, a major focus of current debate is on changes in prevalence over time.

Internationally, statistics from various institutions show decreasing rates of reported child sexual abuse since the early 1990s (cf. Finkelhor et al. 2010). For Germany, too, the data for reported cases in the Police Crime Statistics show a declining trend for child sexual abuse. The number of victims in relation to the population of this age group for child sexual abuse dropped by a total of 4.8 percent between 1994 and 2010 (children and adolescents under the age of 14; offences under sections 176, 176a and $176 \mathrm{~b}$ of the German Criminal Code). Little is so far known, however, about how the prevalence of child sexual abuse has developed in the last two decades on the basis of self-report survey data. Also, there is a lack of knowledge about whether any impact has been made by prevention and intervention strategies implemented to an increased extent during the same period or by public relations and awareness campaigns against child victimisation in particular and intrafamilial violence in general.

Funded by the German Federal Ministry of Education and Research, the present study was carried out to obtain up-to-date, reliable figures on the prevalence of child sexual abuse in Germany and on specific high-risk circumstances, perpetrator-victim relationships, forms of abuse and the behaviours leading up to it, and how abuse is dealt with. The study also focuses on other victimisation experiences (for example in the form of polyvictimisation or revictimisation) in childhood, adolescence and adulthood that may be associated with experiences of sexual abuse. In addition to childhood sexual abuse, the study therefore also covers intrafamilial vio- 
lence and emotional and physical neglect in childhood and adolescence, physical violence in relationships, rape (inside and outside of an intimate relationship or marriage) and stalking.

The study replicates and expands on a much-cited German epidemiological study on child sexual abuse (Wetzels 1997), which was likewise carried out at the Criminological Research Institute of Lower Saxony in 1992 based on a representative German national sample of 16-to-59-yearolds $(3,289$ respondents); this was the only previous representative survey for Germany and is now two decades old.

Because the study design and survey instrument are largely replicated, it is possible to make comparisons, for example to show how the prevalence and severity of sexual abuse and various forms of intrafamilial violence have changed over the last years.

This paper presents up-to-date findings on the prevalence of and trends in the experience of sexual abuse and various perpetrator-victim relationships together with reporting rates from a sample of 16-to-40-year-old men and women (9,175 respondents) of German descent. Both differences between age-cohorts and comparisons with the prior 1992 survey will be reported.

\subsection{Object of investigation and epidemiology}

Child sexual abuse is defined in social science research as a range of acts and behaviours of varying scope. There is currently no standard or generally accepted definition. Instead, many attempts have been made at defining child sexual abuse, each including different aspects (such as physical proximity [with/without physical contact], victim age, victim-perpetrator age gap, intensity of abuse, possible consequences of abuse, and perpetrator intent), in some cases with little overlap and each with different limitations (cf. Wipplinger/Amann 2005). A central feature of child sexual abuse is exploitation of power and control over the child or of a position of authority/dependency (Barnett et al. 2011, Deegener 2005, Engfer 2005 ) independent of the infliction of physical violence on the child (Deegener 2005).

One important factor in identifying sexual abuse is the age limit taken as the age of consent. Epidemiological research usually uses age limits based on legal definitions and hence relates to sexual contact with children and adolescents under 14, 16 or 18 years of age (cf. Deegener 2006). 
Under German law, any (attempted or actual) sexual activity with a child under 14 years is a punishable offence (section 176 of the German Criminal Code). This includes exhibitionism/sexual activity in the presence of a child (section 176 (4) 1). Sexual activity with a 14 or 15-year-old is a punishable offence in certain circumstances (such as when taking advantage of an exploitative situation or for financial reward - section 182 (1) and (2) - or if the adolescent is a minor entrusted to the adult for education or care - section 174). Sexual activity with a 16 or 17 -year-old is likewise a punishable offence if it is in abuse of an exploitative situation or for financial reward (section 182 (1) and (2)) or in abuse of dependence on account of the minor being entrusted to the adult for education or care or subordinate to the adult in a training or employment context (section 174).

A rough behavioural classification of sexual abuse distinguishes acts with and without physical contact (Barnett et al. 2011). Sexual abuse with physical contact includes acts such as anal, oral or vaginal penetration or sexual/genital touching between the child/adolescent and an adult, while non-contact abuse includes sexual acts in the presence of children, exhibiting the genitals for sexual stimulation, and showing pornography (Deegener/Koerner 2005).

Viewed overall, cultural factors also play an important part when it comes to the perception and judgement of sexual behaviour and interactions between children and adults. What is regarded as completely inappropriate sexualised behaviour in one culture may be considered a perfectly normal everyday interaction in another (e.g., parental nudity in the presence of children; Barnett et al. 2011).

The different definitions and inclusion criteria and their differing methodological implementation result in wide variation in reported prevalence rates in social science research. Retrospective identification of sexual abuse experience also differs according to sample type and selection, such as whether the sample is a selective group such as undergraduate students (Elliger/Schoetensack 1991, Bange 1992), school students or vocational school trainees (e.g., Raupp/Eggers 1993) or a representative population sample (Wetzels 1997, Haeuser et al. 2011). The range of prevalence rates found thus varies between about 6 and 25 percent for women and between about 2 and 8 percent for men (Engfer 2005). Finkelhor (2005), in a comparison of epidemiological studies from 20 countries, similarly reports large variation in prevalence rates, ranging between 7 and 36 percent for women and between 3 and 29 percent for men. He ascribes 
this heterogeneity primarily to methodological and definitional differences and less to real country-to-country prevalence differences of the extent suggested by the data. In his own studies, for example, Finkelhor uses his own Juvenile Victimization Questionnaire (JVC; Finkelhor et al. 2011a), in which sexual abuse is measured as lifetime prevalence using seven screening questions (sexual touching, involvement in sexual acts, attempted or completed sexual intercourse, indecent exposure and verbal sexual comments) and a number of follow-up-questions if applicable. Other studies are based on approaches in which sexual abuse is identified using a number of interval-scaled items (such as the Childhood Trauma Questionnaire, Bernstein et al. 2003).

In a recent German study, Haeuser et al. (2011) investigated the prevalence of child sexual abuse (emotional and physical abuse alongside emotional and physical neglect) using the German version of the Childhood Trauma Questionnaire (CTQ; Bernstein et al. 2003) with a representative German sample aged between 14 and 90 (2,504 respondents). Sexual abuse is identified in the CTQ with five items on a five-point scale $(1=$ never to $5=$ very often). The CTQ is based on a very broad definition of sexual abuse with very nonspecific wording (cf. Kappis/Hardt 2005) such as "Someone threatened me unless I did something sexual", "Somebody molested me" or "I believe I was sexually abused". The prevalence rates found in this way were 1.9 percent for 'severe to extreme' sexual abuse (scale values 13 to 25), 4.3 percent for 'moderate to severe' sexual abuse (scale values 8 to 12 ), and 6.3 percent for 'low to moderate' sexual abuse (scale values 6 to 7 ). In total, 12.5 percent of respondents experienced some form of sexual abuse. Consistent with current international research, the risk of becoming a victim of sexual abuse was significantly greater for women than for men.

In another recent study (Bebbington et al. 2010) with a random English national sample ranging in age from 16 to over 75 , sexual abuse was identified with references to acts of varying degrees of severity from unpleasant sexual language directed at the victim to sexual touching and sexual intercourse. In total, 8.3 percent of respondents (11.1 percent of female and 5.3 percent of male respondents) reported having experienced sexual abuse with physical contact (sexual touching or sexual intercourse) before the age of 16 .

These findings are limited in comparability, however, due to the differing methodology for identifying sexual abuse. A recent meta-analysis (Pereda et al. 2009) covering 65 publications (37 studies with male sam- 
ples and 63 studies with female samples) from 22 countries attempted to control for the various definitional and methodological problems and make generalisable conclusions on the prevalence of child sexual abuse. The authors report an average prevalence rate of sexual abuse before the age of 18 of 19.7 percent for women and 7.9 percent for men (19.2 and 7.4 percent with outliers excluded). The studies reported very diverse prevalence rates, varying between 0.2 and 66.9 percent for women and between 0.1 and 87.1 percent for men. Once again, consistent with the research findings to date (with the exception of one study), the prevalence rate for women was greater than that for men by an average across all studies of 2.5:1. In an analysis of the potential influence of various moderator variables on the large identified differences in prevalence, however, the authors were unable to find evidence for the explanations usually given (such as differences in methodological access and sample type, or different ages of consent) (cf. Wynkoop et al. 1995).

A direct comparison of the prevalence of sexual abuse at different points in time (and thus a quasi-longitudinal analysis) is presented by Finkelhor et al. (2010). The researchers compared the answers of two groups of subjects questioned by telephone interview in 2003 and 2008 on their individual sexual abuse experiences up to the age of 17 . Both studies used the items from the Juvenile Victimization Questionnaire (JVQ; Finkelhor et al. 2011a) and are therefore directly comparable in methodological approach. Analysis of sexual victimisation prevalence rates showed a significant decrease from 8.0 (2003) to 6.7 percent (2008), which the authors attributed among other things to intensive violence-prevention and intervention programmes (most of all in schools).

\subsection{Methodology}

\subsubsection{Material}

Taking into account the above-mentioned limitations regarding the comparability of epidemiological studies, a proven survey instrument was selected for the present study in order to trace changes in childhood and adolescent abuse experience in Germany over the last 20 years. The survey material is therefore largely based on the 1992 study by Wetzels (1997) subject only to modifications or additions to the wording in a few places. In regards to child sexual abuse, a question complex was added among other 
things in which respondents are asked if any experiences stated in answer to previous questions were recorded and reproduced/distributed (for example by the perpetrator or someone else) and if so, which experiences, and whether the respondent came to know the perpetrator via the Internet (for example in a social network or chat). This was done to make allowance for recent developments in the use of media for "child grooming" (i.e., approaching and befriending children by using social networks to prepare them gradually for sexual activities).

The survey was carried out using a drop-off questionnaire in combination with a brief prior face-to-face interview. While the brief interview merely covered sociodemographic data (age, gender, educational background, etc.) and two forms of victimisation outside of the family (assault and burglary), the drop-off questionnaire, which respondents completed independently and anonymously in the absence of the interviewer, contained question complexes covering very personal topics relating to victimisation with physical and sexual violence in childhood and adulthood.

It is not possible to tell whether a questionnaire was completed alone or in presence of other people (and whether the fact may have affected the answers) because this was not asked in the questionnaire. Only in the faceto-face interview did the interviewer note if other individuals were present or interrupted the interview.

\subsubsection{Survey conduct and sample recruitment}

While in the 1992 study a random-route sampling design (random selection of starting points of the surveying interviewers, e.g. each $3^{\text {rd }}$ household) was used, for economic reasons the current study is based on a quota sample as also used in other victimisation studies (e.g., Painter/Farrington 1998). The sample is a quota sample that is representative of the privatehousehold (i.e., non-institutionalised) population of Germany with regard to the set of characteristics comprising population distribution among German federal states, urban-rural distribution, age, gender, highest level of education and size of household. The survey was conducted by a field research institute in Nuremberg (Germany) with profound experience in drawing national representative quota samples. Interviewees/study participants were selected and recruited by interviewers in accordance with quota distributions stipulated by the field research institute. Interviewers were advised and trained to select potential participants randomly in order to 
ensure quality of data and representativity as much as possible in a quota sample (Bechhofer/Paterson 2000). Interviewers were asked to send a list with eligible study participants to the field research institute where a central check of quota distributions was conducted and continuously updated. After having obtained the feedback of the field research institute, interviewers could start surveying the respective eligible participants. The survey was carried out between January and May 2011. Out of 12,357 interviews conducted in total, following initial quality control by the field research institute, 11,667 questionnaires were sent to the Criminological Research Institute of Lower Saxony for analysis. After internal checking and elimination, a total of 11,428 data sets remained (taking together the subsamples for respondents of German descent and respondents of Turkish or Russian migration background). A refusal rate cannot be stated as interviewers did not note how many individuals declined to take part in the study when asked.

\subsubsection{Sample description}

The full sample includes 11,428 individuals, of whom 48.1 percent are male and 51.9 percent are female. This paper relates solely to the sub-sample of German descent $(9,175$ respondents). The age range for respondents was set in advance at 16 to 40 years of age, the mean age of the sample was $27.0(S D=7.7$ years $)$.

The 41-to-60-year-olds included in the 1992 study were left out of the present study because a sample of this age group was already surveyed as 22 -to-41-year-olds in 1992. The youngest, 16-to-20 age group was oversampled to allow the finest possible level of analysis for abuse experienced most recently. With regard to the following analyses, this oversampling is offset by weighting. Other key demographic data for the sample are presented in Table 5.1. 
Table 5.1 Key demographic data for the sample (in percent, unweighted data)

\begin{tabular}{|c|c|c|}
\hline \multirow{2}{*}{ Gender } & Female & 52.1 \\
\hline & Male & 47.9 \\
\hline Age (mean) & & 27.04 \\
\hline \multirow{3}{*}{ Age group } & 16 to 20 years & 28.2 \\
\hline & 21 to 30 years & 36.2 \\
\hline & 31 to 40 years & 35.6 \\
\hline \multirow{3}{*}{ Marital status } & Single & 72.7 \\
\hline & Married & 21.4 \\
\hline & Widowed/divorced & 5.4 \\
\hline \multirow{6}{*}{$\begin{array}{l}\text { Level of } \\
\text { education }\end{array}$} & No qualification (or none yet) & 11.7 \\
\hline & Secondary modern school certificate (Hauptschule) & 18.3 \\
\hline & secondary school leaving certificate/O-level (Realschule) & 34.1 \\
\hline & $\begin{array}{l}\text { A-Levels (higher education entrance qualification) or Advanced Vocational } \\
\text { Certificate of Education }\end{array}$ & 22.5 \\
\hline & University or University of Applied Sciences degree & 11.0 \\
\hline & Others & 2.3 \\
\hline \multirow{4}{*}{$\begin{array}{l}\text { Occupational } \\
\text { status }\end{array}$} & At school/in training & 35.1 \\
\hline & Employed & 50.0 \\
\hline & Not employed & 11.8 \\
\hline & Other & 2.5 \\
\hline
\end{tabular}

\subsubsection{Definition and measures of child sexual abuse (CSA)}

To allow for the fact that child sexual abuse is not a clearly defined behaviour pattern and to identify the various forms of sexual abuse as accurately as possible while reflecting different degrees of severity, child sexual abuse was surveyed in the present study with six different specifically described behaviours plus a catch-all 'other sexual activities' category. The wording was taken over in full from the 1992 survey (Wetzels 1997).

The questions relating to each of the seven behaviours constituting sexual abuse were followed by a question complex on the perpetrator-victim relationship, the age of the victim and of the perpetrator on the first and last occurrence, where the abuse took place, and if and when the victim reported the abuse to the police, thus permitting these aspects to be distinguished in the analysis. 
As the instructions (see Figure 5.1) on the question complex show, child sexual abuse is identified in this study as follows:

- Occurrence of at least one of the seven sexual behaviours,

- between a child or adolescent under the age of 16,

- and a person at least five years older (in each case at the time of the first incident).

\section{Fig. 5.1 Description of the scenarios used to measure child sexual abuse (English translation of German original used for the study)}

\footnotetext{
Many children experience, even at a very early age, adults performing sexual acts on them or demanding such acts from them. Such acts can include a broad range of behaviours. In the following you will see listed a range of sexual acts and experiences. Please state how often you experienced any such act in your childhood or adolescence (up to the age of 16) with a person at least five years older than yourself.

How often did it occur in your childhood/adolescence (up to the age of 16) that:

(1) ... a man exposed his genitals in your presence for his own sexual stimulation? (CSA1)

(2) ... a person at least five years older than yourself asked you to touch their genitals or otherwise to sexually stimulate them manually or orally? (CSA2)

(3) ... a person at least five years older than yourself touched your genitals, your breasts or your anus for their own or for your sexual stimulation? (CSA3)

(4) ... a person at least five years older than yourself inserted their finger, their tongue or an object into your vagina or anus for their own or for your sexual stimulation? (CSA4)

(5) ... a man at least five years older than yourself inserted or attempted to insert his penis into your vagina or anus? (CSA5)

(6) ... a man at least five years older than yourself inserted or attempted to insert his penis into your mouth? (CSA6)

(7) In your childhood/adolescence (up to the age of 16) did a person at least five years older than yourself perform other sexual acts (other than those already mentioned) with you or in your presence? (CSA7)
}

To better take into account differences in the legal definition and judgement of sexual acts by an adult towards a child/adolescent, a number of analyses relate to different ages of consent (14 or 16). Responses are classified by age of consent based on the age of respondents at the first reported incident.

In the presentation of the results in the following, the first form of behaviour (CSA1) is discussed as indecent exposure by the perpetrator (for the purpose of sexual manipulation) or exhibitionism and represents one form of child sexual abuse without physical contact. It is not possible to tell in such cases whether the genital exposure took place in the context of further sexual activities (such as touching or penetration) or as a singular act (exhibitionism in the usual sense of the word). Responses to the second to sixth behaviours (CSA2, CSA3, CSA4, CSA5 and CSA6) are collapsed into the category of contact child sexual abuse (contact CSA). This category thus comprises being asked to touch the perpetrator sexually, the per- 
petrator touching the victim's genitals, vaginal or anal penetration of the victim by finger, tongue, object or penis, or oral penetration with the penis. Acts not otherwise specified come under the other sexual activities category, which is shown in all cases as a separate category as it can include sexual acts both with and without physical contact.

\subsection{Findings}

\subsubsection{Prevalence rates}

To identify the prevalence of sexual abuse and the frequency of abuse per victim, subjects were invited to state how frequently they experienced the six specific sexual behaviours on a six-point scale $(1=$ Never to $6=\mathrm{Sev}$ eral times per week). Incidents taking place more than once (answer options 'Twice' to 'Several times a week') were classified as multiple occurrences of abuse. The question relating to experience of 'other sexual acts' had a dichotomous (Yes/No) answer choice; hence no frequency data are available for this category.

Among female respondents, a total of 6.7 percent experienced contact CSA before the age of 16 . While for 2.1 percent of female respondents this was a once-only occurrence, more than twice as many (4.7 percent) were exposed to sexual abuse with physical contact on multiple occasions. A further 5.6 percent of women (additionally ${ }^{1}$ ) experienced exhibitionistic acts (with roughly equal frequencies for single and multiple occurrences) by an adult male and 1.5 percent experienced 'other' sexual activities (see Table 5.2). Among male respondents, 1.4 percent experienced sexual abuse with physical contact before the age of 16 . For male respondents too, sexual abuse with physical contact tended to involve multiple occurrences rather than being a singular event ( 0.5 versus 0.9 percent). Among

1 The three abuse categories are not mutually exclusive and a single individual can have experienced multiple types of abuse and come under more than one category as a result. It is also impossible to tell whether reported experiences of individual abuse scenarios relate to different incidents or a single incident. For example, it cannot be ruled out that a reported experience of exposure by the perpetrator took place in the context of or prior to other sexual abuse behaviours (such as penetration). 
men, 1.4 percent (additionally) experienced exhibitionistic acts before the age of 16 and a further 0.4 percent experienced 'other' sexual activities.

Looking separately at each of the behaviours in the sexual abuse with physical contact category, it becomes clear that the most frequent behaviour was sexual touching, most of all touching of the victim's genitals by the perpetrator (a total of 5.6 percent among women and 1.0 percent among men) or the victim being asked to orally or manually stimulate the perpetrator's genitals (3.4 percent of women and 0.9 percent of men). The least frequently experienced behaviour was oral penetration ( 0.9 percent of women and 0.2 percent of men), but if experienced at all, this tended not to be a once-only but a repeated occurrence, both for women and for men. Overall, women significantly more frequently report being victim to acts of penetration than men, by between 4.5 and 10 times (see Table 5.2). In total, 0.5 percent of male respondents and 2.7 percent of female respondents experienced at least one act of penetration (oral, anal or vaginal) before the age of 16 .

Table 5.2 Prevalence rates of sexual abuse before the age of 16, by single and multiple incidents of abuse, for individual acts and the composite category of abuse with physical contact (in percent, weighted data)

\begin{tabular}{|c|c|c|c|c|c|c|c|c|c|c|}
\hline & \multicolumn{3}{|c|}{$\begin{array}{c}\text { Male } \\
(\mathrm{N}=4391)\end{array}$} & \multicolumn{3}{|c|}{$\begin{array}{c}\text { Female } \\
(\mathrm{N}=4784)\end{array}$} & \multicolumn{3}{|c|}{$\begin{array}{c}\text { Total } \\
(\mathrm{N}=9175)\end{array}$} \\
\hline & & Single & Mult. & Total & Single & Mult. & Total & Single & Mult. & Total \\
\hline CSA 1 & $\begin{array}{l}\text { Indecent exposure by } \\
\text { the perpetrator/ } \\
\text { exhibitionism }\end{array}$ & 0.8 & 0.6 & 1.4 & 2.6 & 3.0 & 5.6 & 1.7 & 1.8 & 3.5 \\
\hline CSA 2 & $\begin{array}{l}\text { Touching of the } \\
\text { perpetrator }\end{array}$ & 0.3 & 0.6 & 0.9 & 1.2 & 2.2 & 3.4 & 0.7 & 1.4 & 2.1 \\
\hline CSA 3 & $\begin{array}{l}\text { Touching of the } \\
\text { victim }\end{array}$ & 0.4 & 0.6 & 1.0 & 2.2 & 3.4 & 5.6 & 1.3 & 2.0 & 3.3 \\
\hline CSA 4 & $\begin{array}{l}\text { Penetration with fin- } \\
\text { ger/tongue/object }\end{array}$ & - & 0.2 & 0.2 & 0.6 & 1.3 & 1.9 & 0.3 & 0.8 & 1.1 \\
\hline CSA 5 & $\begin{array}{l}\text { Anal/vaginal } \\
\text { penetration }\end{array}$ & 0.1 & 0.1 & 0.2 & 0.4 & 1.0 & 1.4 & 0.3 & 0.5 & 0.8 \\
\hline CSA 6 & Oral penetration & - & 0.2 & 0.2 & 0.2 & 0.7 & 0.9 & 0.1 & 0.5 & 0.6 \\
\hline CSA 7 & Other sexual acts & & & 0.4 & & & 1.5 & & & 0.9 \\
\hline $\begin{array}{l}\text { Abuse } \\
\text { (CSA2- }\end{array}$ & $\begin{array}{l}\text { with physical contact }{ }^{1} \\
\text { CSA6) }\end{array}$ & 0.5 & 0.9 & 1.4 & 2.1 & 4.7 & 6.7 & 1.3 & 2.8 & 4.1 \\
\hline
\end{tabular}

Mult. = multiple; totals may contain rounding differences; ${ }^{1}$ The prevalence analysis for abuse with physical contact includes all study participants who experienced at least 
one of the behaviours CSA2 to CSA6; the prevalence rates cannot therefore be taken additively for the five individual behaviours.

The dependence of prevalence rates on underlying definition criteria (such as ages of consent) is once again evident in this sample: Depending on the form of abuse and the respective age of consent, prevalence rates range between 4.6 and 9.4 percent for women and between 1.1 and 2.2 percent for men (see Table 5.3). Taking the legal definition of child sexual abuse in Germany (i.e., based on a consensual age of 14), 1.1 percent of men and 5.2 percent of women experience sexual abuse with physical contact. Including 14 and 15-year-old adolescents (taking an age of consent of 16), 1.4 percent of men and 6.7 percent of women experience sexual acts with physical contact. Just 9.4 percent of women and 2.2 percent of men experienced sexual abuse at least once (including exhibitionism and 'other' sexual activities) before the age of 16 . The gender differences in prevalence rates are statistically highly significant both for the individual behaviours and for the composite categories of sexual abuse with physical contact and sexual abuse overall (at least one experience of abuse out of all seven individual behaviours) (chi square test, $\mathrm{p}<.001$ ).

Table 5.3 Prevalence rates of child sexual abuse, by age of consent ( $N$ resp. in percent; weighted data)

\begin{tabular}{|c|c|c|c|}
\hline \multicolumn{2}{|c|}{ Categories of sexual abuse } & $\begin{array}{c}\text { Male } \\
(\mathrm{N}=4391)\end{array}$ & $\begin{array}{c}\text { Female } \\
(\mathrm{N}=4784)\end{array}$ \\
\hline \multicolumn{4}{|c|}{ Indecent exposure/exhibitionism } \\
\hline \multirow[t]{2}{*}{ Age of consent: } & under 16 & $68(1.5 \%)$ & $248(5.5 \%)$ \\
\hline & under 14 & $62(1.3 \%)$ & $206(4.6 \%)$ \\
\hline \multirow{2}{*}{\multicolumn{4}{|c|}{$\begin{array}{l}\text { Contact CSA } \\
\text { (excluding other sexual activities and indecent exposure/exhibition- } \\
\text { ism) }\end{array}$}} \\
\hline & & & \\
\hline \multirow[t]{2}{*}{ Age of consent: } & under 16 & $67(1.4 \%)$ & $301(6.7 \%)$ \\
\hline & under 14 & $52(1.1 \%)$ & $234(5.2 \%)$ \\
\hline $\begin{array}{l}\text { At least one exp } \\
\text { (including indec } \\
\text { other sexual acti }\end{array}$ & $\begin{array}{l}\text { f CSA (under 16) } \\
\text { ure/exhibitionism, } \\
\text { contact CSA) }\end{array}$ & $104(2.2 \%)$ & $424(9.4 \%)$ \\
\hline
\end{tabular}

Despite the diverging prevalence rates depending on definition criteria, the gender ratio among respondents proves to be highly uniform across all abuse categories. Women thus are four times more likely to fall victim to sexual abuse before the age of 16 as men (proportion of female victims: 
78.4 percent indecent exposure, 81.9 percent abuse with physical contact, 79.3 percent other sexual activities). Wetzels (1997) in his study reported a ratio of about 1:3.

In just under two-fifths (38.4 percent) of cases of contact CSA before the age of 16 , the abuse consisted of acts involving penetration (anal, vaginal or oral); i.e., the majority of cases of sexual abuse with physical contact take the form of sexual touching without any kind of penetration of the victim. There is no significant gender difference regarding penetrative acts (anal, vaginal or oral penetration) as a percentage of all incidents of sexual abuse with physical contact (women: 40.0 percent; men: 31.3 percent; $\left.\chi^{2}(1, \mathrm{~N}=367)=1.74, \mathrm{p}=.19\right)$.

The age at first victimisation with child sexual abuse (under 16) is between 2 and 15 years $(\mathrm{M}=10.4$ years; $\mathrm{SD}=3.2)$ and is relatively homogeneous across all individual categories with the average ranging from 9.6 to 10.7 years. There is no difference here between female $(\mathrm{M}=10.4$ years, $\mathrm{SD}=3.2)$ and male $(\mathrm{M}=10.3$ years, $\mathrm{SD}=3.2)$ respondents.

\subsubsection{Trends in prevalence rates of sexual abuse over the past two decades}

A first indication regarding the trend in the risk of sexual abuse in the past two decades can be obtained by comparing the prevalence rates for the different age groups. ${ }^{2}$ As can be seen from Figure 5.2, the prevalence rates vary considerably between the three age groups. In all three abuse categories, the prevalence of sexual abuse is roughly three times as great in the oldest age group comprising respondents aged 31 to 40 than in the youngest age group comprising respondents aged 16 to 20. Among men, this finding was limited to exhibitionism (indecent exposure) and sexual abuse with physical contact. The 'decline' in the prevalence rates for men is also somewhat less pronounced than for women, with prevalence rates being in the oldest age group about twice as high as in the youngest age group.

2 Because of the oversampling for this age group (before weighting), the youngest age group covers a smaller age range (five years) than the two older age cohorts (10 years each). 
Fig. 5.2 Prevalence rates of child and adolescent sexual abuse (before the age of 16; in percent; weighted data)

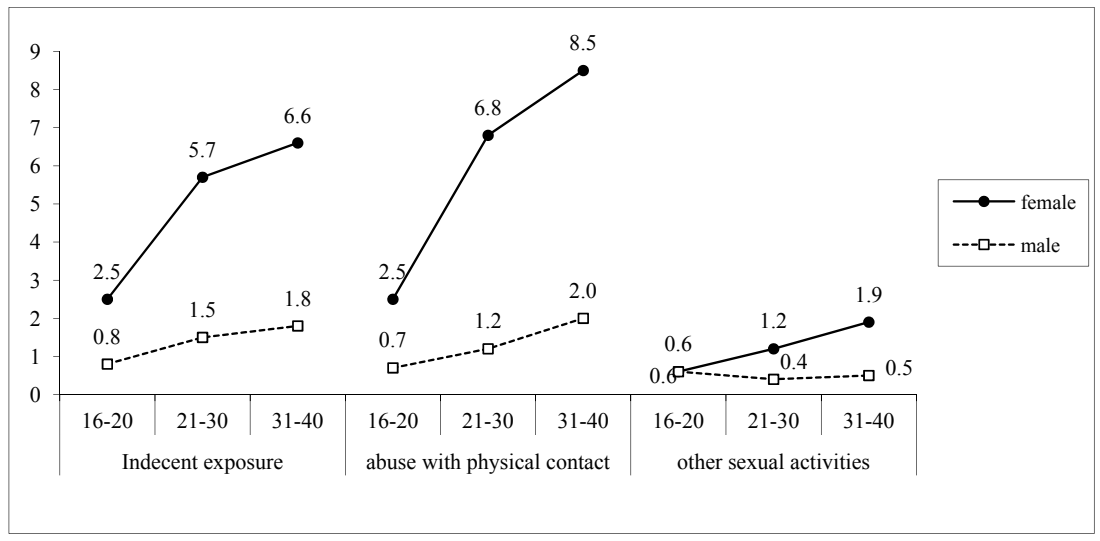

The differences in prevalence rates between age cohorts with regard to contact CSA are significant for male respondents $\left(\chi^{2}(2, \mathrm{~N}=4.663)=\right.$ $9.32, \mathrm{p}<.01)$ and highly significant for female respondents $\left(\chi^{2}(2, \mathrm{~N}=\right.$ $4.475)=32.11, \mathrm{p}<.001)$. With regard to indecent exposure, the differences between age groups are likewise highly significant for female respondents $\left(\chi^{2}(2, \mathrm{~N}=4.470)=18.44, \mathrm{p}<.001\right)$ but not significant for male respondents $\left(\chi^{2}(2, \mathrm{~N}=4.660)=4.16, \mathrm{p}=.13\right)$. With regard to 'other' sexual activities, statistically significant differences between age groups are once again found only for women $\left(\chi^{2}(2, \mathrm{~N}=4.464)=7.23, \mathrm{p}<.05\right)$.

To learn more about potential changes in the prevalence of child sexual abuse, a comparison was made with the original study dating from $1992 .^{3}$

3 As the published prevalence rates from the 1992 survey (Wetzels 1997) relate to a sample with a wider age range (16 to 59) than the present survey, the 1992 sample was restricted to the 16-to-40 age range $(\mathrm{N}=2,162)$ for better comparability. The 1992 data set was also restricted to German respondents (in 1992, origin was identified with nationality - German citizenship: yes/no - and not additionally by reference to migration background as in 2011). The very small group of respondents with other nationalities in $1992-2.4$ percent of the total - was excluded for the presented analysis. The comparisons presented here thus relate for the 1992 survey solely to individuals aged 16 to 40 with German citizenship $(\mathrm{N}=2,098$, of which $\mathrm{n}$ $=1,020$ male and $n=1.078$ female). Although migration background was not additionally recorded in the 1992 survey, it may be assumed that limiting the sample to respondents with German citizenship for 1992 and to German respondents without 
Fig. 5.3 Prevalence of sexual abuse before the age of 16-KFN survey 1992 and 2011 (excluding 'other sexual activities'; in percent; weighted data)

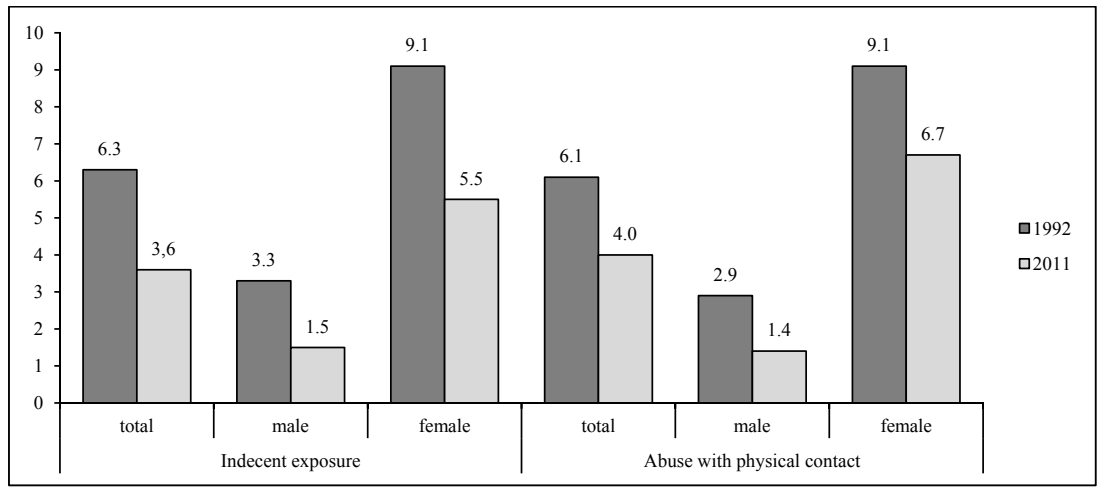

Comparing the prevalence figures from the two studies for contact CSA before the age of 16 supports the trend towards a decline in child sexual abuse discussed above (see Figure 5.3), as the recent prevalence rates for both sexes show a statistically significant difference from the 1992 figures $\left(\chi_{\text {men }}^{2}(1, \mathrm{~N}=5.669)=10.39, \mathrm{p} \leq .001 ; \chi^{2}{ }_{\text {women }}(1, \mathrm{~N}=5.538)=7.35, \mathrm{p}\right.$ $<.01)$. In 1992, 9.1 percent of female respondents and 2.9 percent of male respondents were victims of child sexual abuse with physical contact before the age of 16; in the present study, the figures are 6.7 percent for female respondents and 1.4 percent for male respondents. The proportional decrease in the prevalence of sexual abuse is therefore larger for boys than for girls. With regard to indecent exposure, the prevalence rate fell from 9.1 (1992) to 5.5 percent (2011) for female respondents and from 3.3

migration background for 2011 yields the best possible degree of comparability in view of the changes and developments in migration and naturalisation that have taken place in the intervening years. As naturalisations have increased in the last 10 to 15 years (i.e., essentially since the 1992 survey; see Statistisches Bundesamt, 2011), the percentage of individuals with migration background left over after excluding individuals with non-German citizenship ought to be relatively small. It may also be assumed that only a small percentage of respondents with German citizenship will simultaneously have 'Aussiedler' status (individuals of German descent, primarily from former Eastern Bloc countries, who have claimed German nationality) as few of this group are likely to have been reached by the survey due to language difficulties. 
(1992) to 1.5 percent (2011) for male respondents. This difference (decrease $)$ is once again statistically significant, with $\chi^{2}$ men $(1, \mathrm{~N}=5.665)=$ $15.62, \mathrm{p}<.001 ; \chi^{2}$ women $(1, \mathrm{~N}=5.533)=18.88, \mathrm{p}<.001$.

The statistically significant differences between the two studies (1992 and 2011) are spread equally across the different ages of consent (age $<$ 14: male 2.2 vs. 1.1 percent, female 6.8 vs. 5.2 percent; age $<16$ : male 2.9 vs. 1.4 percent, female 9.1 vs. 6.7 percent). Statistical comparison by age of consent (chi square test) yields significant differences between the genders $(\mathrm{p} \leq .001$ and $\mathrm{p}<.01$ respectively).

\subsubsection{Reporting rates}

Victims were asked for each of the seven abuse behaviours whether the incident(s) were reported to the police. Overall, victims showed relatively little readiness to report occurrences of sexual abuse, for example with a figure of 14.0 percent for sexual abuse with physical contact (Figure 5.4). ${ }^{4}$ The most frequently reported behaviour was exhibitionism (indecent exposure) with 18.7 percent - as also reported by Wetzels (1997).

No significant gender differences with regard to reporting are found for indecent exposure $\left(\chi^{2}(1, \mathrm{~N}=315)=1.72, \mathrm{p}=.19\right)$, sexual abuse with physical contact $\left(\chi^{2}(1, \mathrm{~N}=365)=0.68, \mathrm{p}=.41\right)$ or for other sexual activities $\left(\chi^{2}(1, \mathrm{~N}=77)=0.5, \mathrm{p}=.82\right)$. In all instances, however, female victims show a higher reporting rate than male victims (indecent exposure: female 20.2 percent, male 13.2 percent; sexual abuse with physical contact: female 14.7 percent, male 10.8 percent; other sexual activities: female 14.8 percent, male 12.5 percent).

4 Calculated for respondents who had experienced at least one of the five individual behaviours in the contact CSA category and at least one valid value for the 'Reported' item across all five grouped variables. To count towards the reporting rate for the combined abuse with physical contact variable, a case must feature experience of at least one of the five abuse behaviours with physical violence and having reported at least one of them. No account is given here to how many of any multiple number of sexual abuse behaviours were reported (i.e., for the purposes of the reporting rate, someone who has experienced a single act of abuse and reported it is treated the same as someone who experienced four such acts and reported only two of them). 
Fig. 5.4 Reporting of indecent exposure, contact CSA and other sexual activities, by gender (in percent; weighted data)

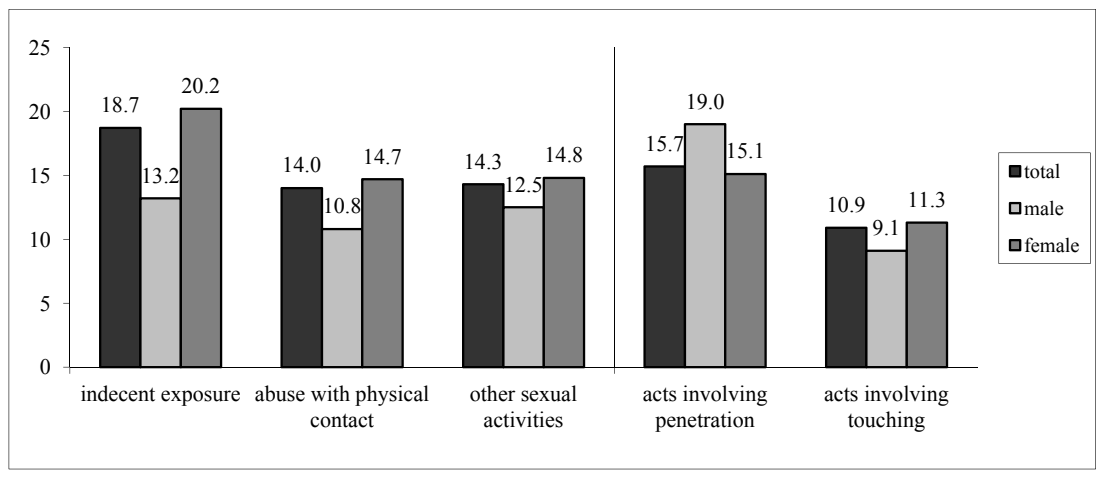

For a closer look at the reporting rates for differing severities of abuse behaviour within the sexual abuse with physical contact variable, an approach similar to Engfer's (2005) categorisation of sexual abuse by intensity was applied, with cases assigned to subcategories separating acts involving touching ('intensive abuse', Engfer 2005) from acts involving oral, anal or vaginal penetration (classified as the most intensive form of abuse, see Engfer 2005). The touching subcategory was strictly limited to cases where no acts involving anal, vaginal or oral penetration were reported. This was to make allowance for the inability to tell whether different acts took place in combination (for example whether a reported offence involving touching took place in combination with a penetration offence such that it was not so much the touching as the penetration that was reported). This could result in the reporting rate for more 'minor' acts of abuse (sexual touching) being overstated. Cases in which at least one act of anal, vaginal or oral penetration (if applicable in combination with touching) are assigned to the penetration category.

If sexual abuse with physical contact is divided as described into acts involving penetration and acts solely involving touching (without the victim additionally experiencing penetration), it emerges that penetration offences are reported significantly more frequently, with a reporting rate of 15.7 percent, than acts solely involving touching of the victim or of the perpetrator by the victim (10.9 percent). There are no significant gender differences in the reporting rates (acts involving touching: female 11.3 percent, male 9.1 percent; acts involving penetration: female 15.1 percent, 
male 19.0 percent $\left.) ; \chi_{\text {touching }}(1, \mathrm{~N}=221)=0.18, \mathrm{p}=.67\right) ; \chi_{\text {penetration }}(1, \mathrm{~N}$ $=140)=0.21, \mathrm{p}=.65$.

An analysis of reporting rates by age group (see Figure 5.5) provides indications of a change in the tendency to report child sexual abuse in recent decades. Both indecent exposure $\left(\chi^{2}(2, \mathrm{~N}=315)=11.96, \mathrm{p}=.001\right)$ and sexual abuse with physical contact $\left(\chi^{2}(2, \mathrm{~N}=366)=14.86, \mathrm{p} \leq .001\right)$ show (highly) significant differences in reporting rates between age groups. This takes the form of increasing propensity to report, with reporting rates at their lowest in the oldest age groups and at their highest in the youngest (e.g., abuse with physical contact: 16-to-20-year-olds 34.6 percent versus 9.0 percent in 31-to-40-year-olds). No significant differences emerge on the other hand for other sexual activities $\left(\chi^{2}(2, \mathrm{~N}=78)=1.11\right.$, $\mathrm{p}=.57)$, for which there is also no identifiable trend across age groups.

Fig. 5.5 Reporting rates for indecent exposure, sexual abuse with physical contact and other sexual activities, by age group (in percent; weighted data)

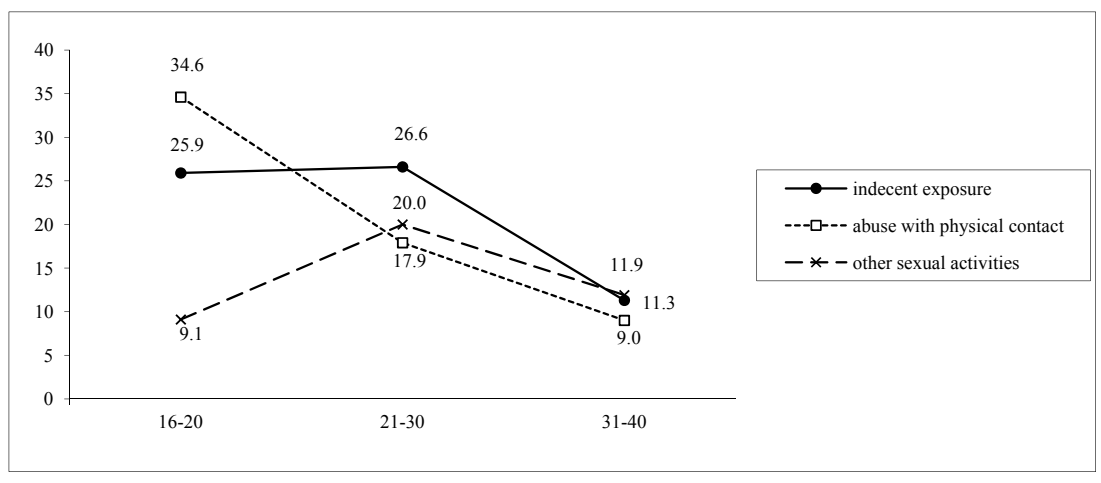

According to the Police Crime Statistics (Bundesministerium des Inneren, 2010; Figure 5.6), reported cases of child sexual abuse (offences under sections 176, 176a and 176b of the German Criminal Code) declined by 27.4 percent among female and 24.4 percent among male victims between 1994 and 2010. In light of the increasing propensity to report just described, this can be taken as further evidence of the declining trend in child sexual abuse shown by the self-report survey data. The combination of findings from reported cases and self-report surveys also shows the decline in cases of child sexual abuse to be even more pronounced than is evident from the Police Crime Statistics time series. 
Fig. 5.6 Trend in reported cases of child sexual abuse (offences under sections 176, $176 a$ and $176 b$ of the German Criminal Code) as shown in the Police Crime Statistics, 1994 to $2010^{5}$

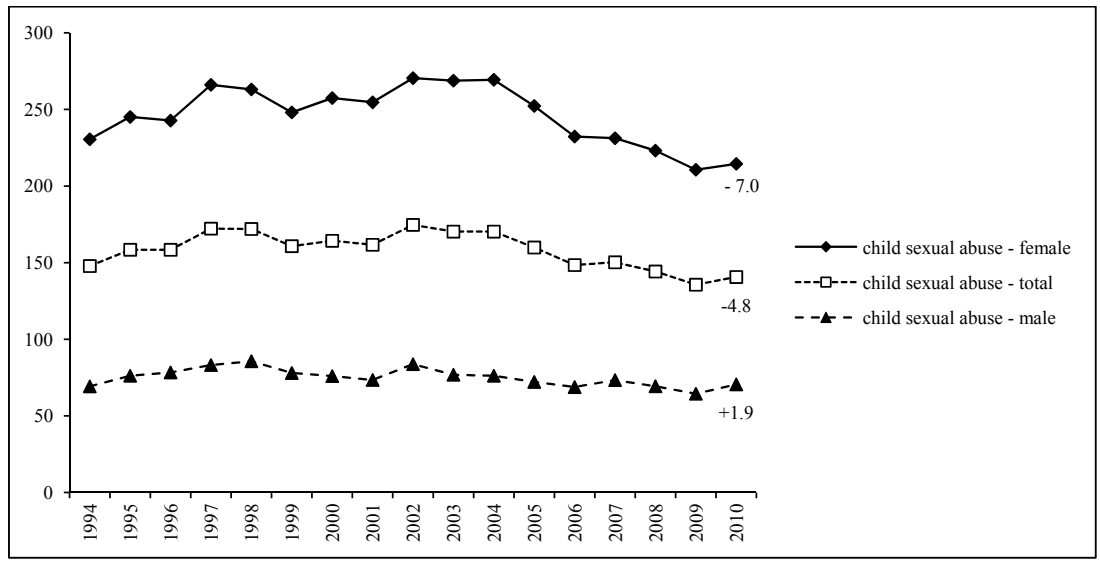

\subsubsection{Perpetrators of child and adolescent sexual abuse}

The question concerning the perpetrators of sexual abuse contained an extensive list of items from which respondents were asked to select all that applied. One fact that stands out with regard to the overall sample of 16to-40-year-olds is that for indecent exposure, in by far the largest number of cases (39.9 percent) the perpetrator was identified as an unknown male individual. These unknown perpetrators can probably be assumed to be 'conventional' exhibitionists who gain sexual simulation by displaying their genitals to a male or female victim, usually in a public place, without any further sexual act being involved (such as acts involving physical contact with the victim). With other perpetrators - those known or related to their victims - acts of exhibitionism are less likely to be singular acts and more likely to be accompanied by or precede other forms of sexual abuse. In the case of exhibitionism by unknown perpetrators, too, however, it

5 The figures shown are the number of victims of child sexual abuse (children/adolescents under 14; offences under sections 176, 176a and 176b of the German Criminal Code) per 100,000 inhabitants adjusted for the size of each group as a percentage of the population. 
cannot be ruled out that the indecent exposure may take place in conjunction with other acts of abuse (with physical contact). Female perpetrators were not cited as a result of the question on this offence being asked solely in relation to male perpetrators.

With regard to contact CSA (Figure 5.7), the perpetrators as cited by both female and male respondents are predominantly male relatives ${ }^{6}$ (female respondents: 32.4 percent; male respondents: 27.0 percent) and male acquaintances $^{7}$ (female respondents: 29.8 percent; male respondents: 19.1 percent). Among female respondents, the perpetrator was identified in 9.2 percent of cases as the natural father and in 9.7 percent as the stepfather; among male respondents, the equivalent figures were 7.4 percent and 12.3 percent. For both sexes, the perpetrator was thus identified in just under 20 percent of cases as the father or the stepfather. Uncles were cited most frequently when it came to male relatives (female respondents: 9.1 percent; male respondents: 15.4 percent). Taking male relatives and the separate figures for fathers and stepfathers together, about half of all perpetrators are identified by both sexes as members of the family.

Overall, female perpetrators are cited very rarely, but when they are it is primarily by male victims (15.1 percent). The latter finding is most evident for other sexual activities. More male respondents than female respondents cite female perpetrators in this category (38.5 versus 1.7 percent). Female perpetrators of child and adolescent sexual abuse thus appear to display a clearer preference for victims of the opposite sex than do male perpetrators, who account for a very large proportion of perpetrators for male victims. It should be taken into account in this connection, however, that victim gender preference among perpetrators, who are predominantly male in any case, is already reflected in the roughly four-fold higher incidence of female victims. Engfer (2005) additionally notes that the proportion of female perpetrators generally tends to be underestimated, as physical contact with children is more a part of everyday life for women

6 The male relatives category does not include fathers and stepfathers. These are reported separately. The male relatives category comprises relatives such as grandfathers, uncles, brothers and male cousins.

7 With regard to the male acquaintances category, respondents were able to provide specific information on the perpetrator in response to an open question. The category includes acquaintances such as neighbours, friends and acquaintances of the victim or of his or her parents, brothers and sisters or friends, and perpetrators from the school/leisure activities context. 
and is less readily perceived as overstepping a limit; plus, male victims of sexual abuse by older women less frequently perceive themselves as victims.

Fig. 5.7 Distribution of combined groups of perpetrators of sexual abuse with physical contact before the age of 16, by gender (Multiple responses possible; in percent; weighted data)

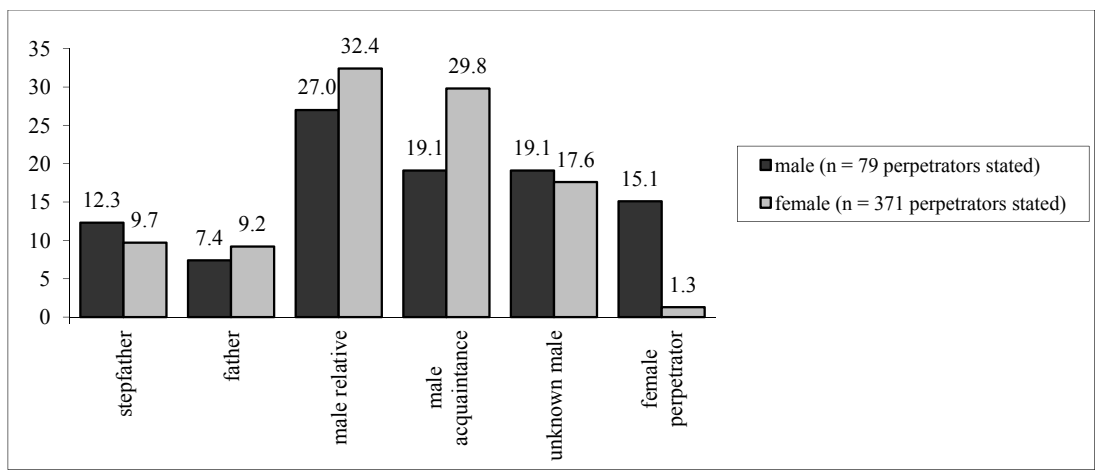

An analysis of perpetrators by age cohort (Table 5.4) shows that the described decrease in sexual abuse in the last three decades appears to relate primarily to sexual abuse in the family. Thus, in parallel with the continuous decline in cases, male relatives accounted for a significantly smaller percentage of all perpetrators for 16-to-20-year-old respondents (26.7 percent) than for 31-to-40-year-old respondents (51.7 percent). It should be noted here that although there has indeed been a shift in the relative share of unknown male perpetrators when it comes to abuse with physical contact (from 15.8 percent for 31-to-40-year-old respondents to 33.6 percent for 16-to-20-year-old respondents), this does not imply a heightened risk of abuse from such perpetrators. With the prevalence of abuse declining overall, the percentage increase merely means that the number of offences committed by unknown perpetrators has tended to remain unchanged (rather than decreasing with the number committed by perpetrators in the family). The relative share of male acquaintances among perpetrators of abuse with physical contact has held near-constant over the three decades. When interpreting these figures, however, it is necessary to take into account the limitations imposed by the large difference in the number of perpetrators cited by each age cohort ( $n=27$ for 16-to-20-year-olds versus $n$ $=255$ for 31-to-40-year-olds). 
Table 5.4 Distribution of combined groups of perpetrators by age cohort (in percent; weighted data)

\begin{tabular}{l|ccc|ccc|ccc}
\hline & \multicolumn{3}{|c|}{ Indecent exposure } & \multicolumn{3}{c|}{$\begin{array}{c}\text { Abuse with physical } \\
\text { contact }\end{array}$} & \multicolumn{3}{c}{ Other sexual activities } \\
& $16-20$ & $21-30$ & $31-40$ & $16-20$ & $21-30$ & $31-40$ & $16-20$ & $21-30$ & $31-40$ \\
\hline Perpetrators stated & 28 & 142 & 186 & 27 & 168 & 255 & 9 & 26 & 51 \\
\hline Male relatives & 24.3 & 42.2 & 44.5 & 26.7 & 51.4 & 51.7 & 32.4 & 46.2 & 51.6 \\
\hline Male acquaintances & 15.5 & 19.1 & 17.7 & 37.2 & 26.7 & 27.8 & 8.5 & 14.6 & 31.2 \\
\hline Unknown males & 60.2 & 38.7 & 37.8 & 33.6 & 18.4 & 15.8 & 30.4 & 33.5 & 10.1 \\
\hline Female perpetrators & -- & -- & -- & 2.5 & 2.5 & 4.7 & 28.7 & 5.7 & 7.1 \\
\hline
\end{tabular}

Multiple responses possible

\subsection{Discussion}

The prevalence rates for sexual abuse determined in the present study 6.7 percent among women and 1.4 percent among men for abuse with physical contact before the age of 16 - are at the lower end of the spectrum compared with the range found across different studies (cf. Pereda et al. 2009). The prevalence rates are also lower than the German study by Haeuser et al. (2011) carried out in the same year. Given the large differences in definitions (the CTQ covers a broader and less specific range of behaviours than the specific sexual behaviours surveyed in the present study) and the substantially larger age range sampled in Haeuser et al. (2011), it is scarcely possible to compare with the present study (or for that matter with the study by Wetzels (1997), as Haeuser et al. (2011) themselves note). It is conceivable for example - looking at the lower prevalence rates in younger age groups - that the lower prevalence rates partly reflect the young age structure of the sample in the present study relative to that used by Haeuser et al. (2011).

The indications of declining prevalence rates of sexual abuse with regard to the forms of abuse surveyed here are also supported by findings from international studies (cf. Bebbington et al. 2010, Finkelhor et al. 2010, Laaksonen et al. 2011). Bringing together various US studies, for example, Finkelhor et al. (2010) likewise report decreases in sexual abuse between 1993 or 1995 and 2005. The authors additionally report from studies of their own (telephone surveys of 2-to-17-year-old children and adolescents or their closest caregivers) significantly lower prevalence rates for sexual abuse in 2008 compared with 2003. 
Bebbington et al. (2010), in their study based on a random sample of English households (7,353 respondents) featuring an age-group-specific analysis of three age cohorts between the ages of 16 and 44, similarly identified a decline in prevalence rates through the age groups from 35to-44-year-olds down to 16-to-24-year-olds (with prevalence rates of 10.7, 8.0 and 6.6 percent). Interestingly, although the prevalence rates held broadly constant around 10 percent for the three age groups between the ages of 35 and 64, prevalence rates were significantly lower again in the two oldest age groups (ages 65 to 74 and over 75, at 6.1 and 2.7 percent). This effect can be interpreted by drawing on cognitive psychology, as events tend to be recalled less readily (i.e., less frequently) the further removed they are from the present (cf. Solso 2005), hence if the incidence rate stays constant, retrospective recall of events from childhood or adolescence would be expected to result in the lowest prevalence rate in the oldest age group. The differences between cohorts in the study presented in this paper, on the other hand, run contrary to these expectations and may therefore speak in favour of a real decrease. This conclusion is also supported when comparing the present data with findings from Wetzels (1997), where for three age cohorts closely equivalent to the present study - ages 16 to 20,21 to 29 and 30 to 39 - only minor differences were found regarding sexual abuse with physical contact (male respondents: 2.9, 2.8 and 2.9 percent; female respondents: $9,9.6$ and 10 percent). With regard to the lower prevalence rates found for each of the oldest age cohorts in his study, Wetzels (1997) notes as additional factors to be taken into account when interpreting age cohort comparisons the possibly lesser readiness of older age groups to talk about sexual topics (cf. Casey/Nurius 2006) and the greater sensitisation of younger age groups to sexuality-related topics that has largely come about through increased public airing of such topics. In light of the young age structure of the sample in the present study, such factors may be assumed to play a lesser part here; if that is the case, however, it would speak even more strongly in favour of the decrease in prevalence rates being real.

It must also be noted at this point, however, that mechanisms such as memory repression or suppression in connection with traumatic experiences may continue to operate with effects whose persistence is hard to estimate. For example, it is conceivable that repression of traumatic abuse experiences might be more pronounced in the youngest age group (for whom the abuse is most recent) than in older age groups, with the result of the abuse not (yet) being accessible to conscious memory, thus providing 
one explanation for the lower prevalence rates in younger age groups. In a prospective study Williams (1994) was able to show that of 129 women with documented experiences of sexual abuse between the age of 10 months and 12 years, 38 percent were unable to recall the experience when surveyed about their childhood 17 years later. This applied most of all for those whose abuse took place at a very young age or for whom the perpetrator was someone they knew. A more recent study by Goodman et al. (2003), on the other hand, found that of 175 surveyed individuals with documented sexual experiences of abuse, 81 percent were able to say in interview that they had been abused. Factors identified by the authors as relevant to whether the abuse was reported in interview included being older when the abuse ceased, maternal support after the abuse came out, and severity of the abuse experience. The authors conclude that if people do not report a recollection of abuse, the cause is not necessarily memory inaccessibility, and that such inaccessibility applies in only a small number of cases. Viewed from the opposite direction, there were still 20 percent who did not state/recall having been abused, hence it may be assumed that epidemiological studies based on retrospective self-reporting such as the present study tend if anything to underestimate the actual incidence of abuse. Whether this underestimation is spread systematically across age cohorts is something that cannot be judged due to the many different influencing factors (see above). It must be noted with regard to the studies targeting the recall validity of traumatised individuals, however, that the samples used are very specific (comprising respondents whose abuse is documented and are surveyed in a follow-up to treatment or intervention; cf. Hardt/Rutter 2004).

The supplementary analysis of perpetrators by age cohorts showed that the identified decline in sexual abuse primarily relates to abuse in the family. This trend is also reported by Casey and Nurius (2006) in a study of a household sample of 18-to-96-year-old women (1,325 respondents) from the State of Washington. This is an indication that the increased efforts since the early 1990s to raise awareness of (sexually) transgressive acts towards and their effects on children, together with the resulting prevention efforts, have been particularly effective in this context. Another potential explanation is that is has become easier in the last 20 years to impose (spatial) separation in cases of violence and problem relationships (for example under Germany's Protection from Violence Act 2002). Apart from that, various legislative changes in Germany have had an overall effect on intrafamilial violence, including marital rape being made punishable 
(1997) and abolition of the parental right to administer corporal punishment (2000). Taking into account the fact that children who experience sexual abuse frequently face violence on multiple fronts within the family (such as interparental violence and physical maltreatment; cf. Wetzels 1997), effective intervention in domestic physical and sexual violence may be expected to lower the risk of intrafamilial sexual abuse for any children. It can also be concluded from the empirically proven correlation between the various forms of child maltreatment and abuse (cf. Haeuser et al. 2011, Wetzels 1997) that the decline in sexual abuse - and notably sexual abuse in the family - is partly an indirect consequence of abolition of the parental right of corporal punishment (2000) and, hand in hand with that, increasing awareness in favour of non-violent child-rearing. Whether the decline in sexual abuse is accompanied by declining prevalence rates for other forms of victimisation in childhood and adolescence (such as neglect or physical maltreatment) and by a general decline in violence in the family (including interparental physical and sexual violence) is something that remains to be examined in further analysis of the data. A number of studies already provide empirical evidence of parental physical violence in particular having declined in Germany since the 1990s (Baier 2008, Brettfeld/Wetzels 2004, Bussmann 2005).

The rising reporting rates in the last 20 years may be seen as an expression of social change in which child sexual abuse has come under increasingly explicit condemnation and victims have been increasingly enabled in consequence both to perceive abuse for what it is and to make it public. This conclusion is corroborated by findings from other studies (cf. Casey/ Nurius 2006, Finkelhor et al. 2011b). From the perpetrator perspective, the resulting heightened risk of discovery may act as a deterrent and thus represent a further explanatory factor for the decline in the forms of child sexual abuse (notably those with physical contact) reported in the present study. To what extent this leads, however, to more anonymous forms of child and adolescent sexual abuse (for example via Internet forums) is something that cannot be answered here.

In summary, the findings of the present study may first of all give reason to conclude that in terms of prevention, public relations work, the establishment of intervention and support for victims and the committed work of victim counselling services, the efforts already underway are going in the right direction. At the same time, the finding that 6.7 percent of surveyed 16-to-40-year-old women of German descent and 1.4 percent of men experienced sexual abuse with physical contact before the age of 16 
shows that much remains to be done. Additionally, while reporting rates for sexual abuse have increased, it must not be forgotten that sexual abuse - including in its severe forms abuse featuring penetration - is still a crime that is rarely reported overall (14.0 percent of cases of sexual abuse with physical contact before the age of 14). In other words, the majority of sexual abuse still goes unreported. It must therefore be assumed that many sexually abused children still do not (and cannot) receive the support they need.

There are some additional methodological limitations that must be taken into consideration when interpreting the findings and with regard to their suitability for generalisation. Thus due to the sample type and recruitment method - a quota sample recruited by commissioned interviewers according to stipulated quota characteristics - certain groups were not reached, some of which may display heightened prevalence of sexual victimisation (such as patients in psychiatric clinics, prison inmates, residents of care homes for people with mental and/or physical disabilities, homeless people, prostitutes, and people in the drug scene). Reference is made in this regard to a study just completed on the living situation of and pressures faced by women with impairments and disabilities in Germany (Schroettle et al. 2011), the first study of its kind in Germany to collate representative data on violence and abuse experienced by women with disabilities. The study shows that women with disabilities and impairments are between two and three times more likely to have been victims of sexual abuse in childhood and adolescence than the average for women in the German population as a whole, and represent a particularly vulnerable group with regard to sexual violence and abuse. This should be taken into account when interpreting the findings to the extent that the figures reported here must be considered a bottom limit and relate to unreported cases in a population segment that excludes groups such as those just mentioned. All population-based self-report surveys of this kind are subject to the same problem, however (including, for example, telephone surveys as in Finkelhor et al. 2010). To this extent it is indeed possible - while allowing for differences in methodology and definition - to compare the findings with those of other representative surveys. This applies in particular to the 1992 study in which Wetzels (1997) noted similar limitations.

Besides the systematic inability to reach certain groups of the population, another potential and unquantifiable limitation to the representativeness of the data is lack of knowledge about any selection effects regarding individuals' propensity to participate. For example it is possible that indi- 
viduals with experiences corresponding to the nature of the survey may take part precisely because they have something to report. On the other hand, the opposite could also be the case, with a greater refusal rate among victims explicitly wanting to avoid giving details about their victimisation (cf. Hardt 2005). Edwards et al. (2001), however, found no significant differences in abuse experience between respondents who participated and those who refused. The slight differences that they did identify went in the direction of people who have experienced abuse tending more to take part in surveys than to refuse. Another limitation in this context is that a refusal rate cannot be stated as interviewers did not note how many potential study participants they contacted and how many of these finally refused their participation.

Finally, regarding interpretation of the declining rates of sexual abuse in the last two decades, it is expressly pointed out that these relate solely to 'conventional' forms of sexual abuse specifically included in the survey. The study is unable to answer whether there has been a shift within or diversification of forms of abuse. For example, with the huge growth in new media (such as mobile Internet, texting and picture messaging, ubiquitous camera phones, chat rooms, social networks and video telephony) compounded by children and adolescents having early access to such media and the resulting proliferation of opportunities (easier access to pornography, means of recording sexual contacts with children and sharing the recorded content, and the ability to enter into contact with children and adolescents anonymously in social networks), abuse with physical contact may now have made way for other forms of child sexual abuse that are not explicitly covered by the study (although they may be included in the not further specified category 'other sexual activities').

\section{References}

Baier, D. (2008). Entwicklung der Jugenddelinquenz und ausgewählter Bedingungsfaktoren seit 1998 in den Städten Hannover, München, Stuttgart und Schwäbisch Gmünd. Kriminologisches Forschungsinstitut Niedersachsen: KFN: Forschungsbericht Nr. 104.

Bange, D. (1992). Die dunkle Seite der Kindheit. Köln: Volksblatt Verlag.

Barnett, O. W., Miller-Perrin, C. L., Perrin, R. D. (2011). Family Violence Across the Lifespan: An Introduction. Thousand Oaks: Sage Publications. 
Bebbington, P. E., Jonas, S., Brugha, T., Meltzer, H., Jenkins, R., Cooper, C., King, M., McManus, S. (2010). Child Sexual Abuse Reported by an English National Sample: Characteristics and Demography. Social Psychiatry and Psychiatric Epidemiology, 46, 255-262.

Bechhofer, F., Paterson, L. (2000). Principles of Research Design in the Social Sciences. London: Routledge.

Bernstein, D.P., Stein J. A., Newcomb M.D., Walker, E., Pogge, D., Ahluvalia, T., Stokes, J., Handelsman, L., Medrano, M., Desmond, D., Zule, W. (2003). Development and Validation of a Brief Screening Version of the Childhood Trauma Questionnaire. Child Abuse \& Neglect, 27, 169-190.

Brettfeld, K., Wetzels, P. (2004). Über die präventive Kraft des Wissens. Zum gesellschaftskritischen Potential und kriminalpolitischem Nutzen kriminologischer Dunkelfeldforschung. In: K.-M. Karliczek (Ed.), Kriminologische Erkundungen. Wissenschaftliches Symposium aus Anlass des 65. Geburtstages von Klaus Sessar (p. 226-265). Münster: Lit.

Bundesministerium des Inneren (Eds.) (2010). Polizeiliche Kriminalstatistik: Deliktarten Zeitreihe 1993-2010. Berlin: Bundesministerium des Inneren.

Bussmann, K.-D. (2005). Report über die Auswirkungen des Gesetzes zur Ächtung der Gewalt in der Erziehung. Bundesministerium der Justiz. Verfügbar unter: http:// bussmann.jura.uni-halle.de/publikationen/ [19.12.2011].

Casey, E. A., Nurius, P.S. (2006). Trends in the Prevalence and Characteristics of Sexual Violence: A Cohort Analysis. Violence \& Victims, 21, 629-644.

Deegener, G. (2005). Kindesmissbrauch. Erkennen, Helfen, Vorbeugen. Weinheim und Basel: Beltz.

Deegener, G. (2006). Erscheinungsformen und Ausmaße von Kindesmisshandlung. In: W. Heitmeyer, M. Schroettle (Eds.), Gewalt. Beschreibung, Analysen, Prävention (p. 26-44). Bonn: Bundeszentrale für politische Bildung.

Deegener, G., Körner, W. (2005). Kindesmisshandlung und Vernachlässigung. Ein Handbuch. Göttingen: Hogrefe.

Edwards, V. J., Anda, R. F., Nordenberg, D. F., Felitti, V. J., Williamson, D. F., Howard, N., Wright, J. A. (2001). Bias Assessment for Child Abuse Survey: Factors Affecting Probability of Response to a Survey About Child Abuse. Child Abuse \& Neglect, 25, 307-312.

Engfer, A. (2005). Formen der Misshandlung von Kindern - Definitionen, Häufigkeiten, Erklärungsansätze. In: U. T. Egle, S. O. Hoffmann, P. Joraschky, (Eds.), Sexueller Missbrauch, Misshandlung, Vernachlässigung (p. 3-19). Stuttgart: Schattauer.

Elliger, T. J, Schoetensack, K. (1991). Sexueller Missbrauch von Kindern - eine kritische Bestandsaufnahme. In: G. Nissen (Ed.), Psychogene Psychosyndrome und ihre Therapie im Kindes- und Jugendalter (p. 143-154). Bern: Huber.

Finkelhor, D. (2005). Zur internationalen Epidemiologie von sexuellem Missbrauch an Kindern. In: G. Amman, R. Wipplinger (Eds.), Sexueller Missbrauch - Überblick zu Forschung, Beratung und Therapie. Ein Handbuch. (3rd Ed.) (p. 81-94). Tübingen: dgvt-Verlag. 
Finkelhor, D., Hamby, S., Turner, H., Ormrod, R. (2011a). The Juvenile Victimization Questionnaire: $2^{\text {nd }}$ Revision (JVC-R2). Durham, NH: Crimes Against Children Research Center.

Finkelhor, D., Ormrod, R., Turner, H., Hamby, S. (2011b). School, Police, and Medical Authority Involvement With Children Who Have Experienced Victimization. Archives of Pediatrics \& Adolescent Medicine, 165, 9-15.

Finkelhor, D., Turner, H., Ormrod, R., Hamby, S. L. (2010). Trends in Childhood Violence and Abuse Exposure. Evidence From 2 National Surveys. Archives of Pediatrics \& Adolescent Medicine, 164, 238-242.

Goodman, G. S., Ghetti, S., Quas, J. A., Edelstein, R. S., Alexander, K. W., Redlich, A. D., Cordon, I. M., Jones, D. P. (2003). A Prospective Study of Memory for Child Sexual Abuse: New Findings Relevant to the Repressed-Memory Controversy. Psychological Science, 14, 113-118.

Hardt, J., Rutter, M. (2004). Validity of Adult Retrospective Reports of Adverse Childhood Experiences: Review of the Evidence. Journal of Child Psychology and Psychiatry, 45, 260-273.

Haeuser, W., Braehler, E., Schmutzer, G., Glaesmer, H. (2011). Misshandlungen in Kindheit und Jugend - Ergebnisse einer Umfrage in einer repräsentativen Stichprobe der deutschen Bevölkerung. Deutsches Ärzteblatt, 108, 287-94.

Kappis, B., Hardt, J. (2005). Standardisierte Verfahren zur retrospektiven Erfassung von Kindheitsbelastungen. In: P. Joraschky, U.T. Egle, S.O. Hoffman (Eds.). Sexueller Missbrauch, Misshandlung, Vernachlässigung - Erkennung, Therapie und Prävention der Folgen früher Stresserfahrungen. (3rd Ed.). Stuttgart: Schattauer.

Laaksonen, T., Sariola, H., Johansson, A., Jerna, P., Varjonen, M., von der Pahlen, B., Sandnabba, N.K., Santtila, P. (2011). Changes in the Prevalence of Child Sexual Abuse, Its Risk Factors, and Their Associations as a Function of Age Cohort in a Finnish Population Sample. Child Abuse \& Neglect, 35, 480 - 490.

Painter, K., Farrington, D.P. (1998). Marital Violence in Great Britain and its Relationship to Marital and Non-marital Rape. International Review of Victimology, 5, 257-276.

Pereda, N., Guilera, G., Forns, M., Gómez-Benito, J. (2009). The Prevalence of Child Sexual Abuse in Community and Student Samples: A Meta-Analysis. Clinical Psychology Review, 29, 328-338.

Raupp, U., Eggers, C. (1993). Sexueller Missbrauch von Kindern. Eine regionale Studie über Prävalenz und Charakteristik. Monatsschrift für Kinderheilkunde, 141, 316-322

Schroettle, M., Hornberg, C., Glammeier, S., Sellach, B., Kavemann, B., Puhe, H., Zinsmeister, J. (2011). Lebenssituation und Belastungen von Frauen mit Beeinträchtigungen und Behinderungen in Deutschland. Kurzzusammenfassung der zentralen Ergebnisse. Verfügbar unter: http://www.uni-bielefeld.de/IFF/for/for-gewffmb.html [19.12.2011 ].

Solso, R. L. (2005). Kognitive Psychologie. Heidelberg: Springer Medizin Verlag. 
Statistisches Bundesamt (2007). Bevölkerung und Erwerbstätigkeit - Bevölkerung mit Migrationshintergrund. Ergebnisse des Mikrozensus 2005 (Fachserie 1 Reihe 2.2). Wiesbaden: Statistisches Bundesamt.

Wetzels, P. (1997). Gewalterfahrungen in der Kindheit. Sexueller Missbrauch, körperliche Mißhandlung und deren langfristige Konsequenzen - Interdisziplinäre Beiträge zur kriminologischen Forschung. Baden-Baden: Nomos Verlagsgesellschaft.

Williams, L. M. (1994). Recall of Childhood Trauma: A Prospective Study of Women's Memories. Journal of Consulting and Clinical Psychology, 62, 1167-1176.

Wipplinger, R., Amann, G. (2005). Sexueller Missbrauch - Überblick zu Forschung, Beratung und Therapie. Ein Handbuch (3rd. Ed.). Tübingen: dgvt-Verlag.

Wynkoop, T. F., Capps, S. C., Priest, B. J. (1995). Incidence and Prevalence of Child Sexual Abuse: A Critical Review of Data Collection Procedures. Journal of Child Sexual Abuse, 4, 49-67. 